\title{
Relationship Between Estrogen Receptor Co-regulators and Histological Grade in Estrogen-Dependent Invasive Breast Cancer
}

\author{
Berti Nelwan ${ }^{1}$, Ilhamjaya Pattelongi ${ }^{2}$, Muhammad Nasrum Massi ${ }^{3}$, Tjakra Manuaba ${ }^{4}$, \\ Cahyono Kaelan', Suryani As'ad ${ }^{5}$, Johanna Kandouw ${ }^{1}$, Syarifuddin Wahid ${ }^{1}$, Mochammad Hatta ${ }^{3}$, * \\ ${ }^{1}$ Department of Pathological Anatomy, Faculty of Medicine, Hasanuddin University, Makassar, Indonesia \\ ${ }^{2}$ Department of Physiology, Faculty of Medicine, Hasanuddin University, Makassar, Indonesia \\ ${ }^{3}$ Department of Medical Microbiology, Faculty of Medicine, Hasanuddin University, Makassar, Indonesia \\ ${ }^{4}$ Deparment of Surgical Oncology, Faculty of Medicine, Udayana University, Denpasar, Indonesia \\ ${ }^{5}$ Department of Clinical Nutrition, Faculty of Medicine, Hasanuddin University, Makassar, Indonesia
}

Email address:

nelwanb@gmail.com (B. Nelwan), ilham_pt@yahoo.com (I. Pattelongi), nasrumm2000@yahoo.com (M. N. Massi), breastca04@yahoo.com (T. Manuaba), cakaelan@yahoo.com (C. Kaelan), suryani_fkuh@yahoo.com (S. As'ad), patologi.unhas@gmail.com (J. Kandouw), syarifuddin_wahid@yahoo.com (S. Wahid), hattaram@indosat.net.id (M. Hatta) ${ }^{*}$ Corresponding author

\section{To cite this article:}

Berti Nelwan, Ilhamjaya Pattelongi, Muhammad Nasrum Massi, Tjakra Manuaba, Cahyono Kaelan, Suryani As'ad, Johanna Kandouw, Syarifuddin Wahid, Mochammad Hatta. Relationship Between Estrogen Receptor Co-regulators and Histological Grade in EstrogenDependent Invasive Breast Cancer. American Journal of Clinical and Experimental Medicine. Vol. 4, No. 3, 2016, pp. $34-42$. doi: 10.11648/j.ajcem.20160403.11

Received: January 18, 2016; Accepted: February 9, 2016; Published: April 1, 2016

\begin{abstract}
The study aims to assess the relationship between level expression co-regulators of estrogen receptor (SRC1, $\mathrm{CBP} / \mathrm{p} 300, \mathrm{NCoR}, \mathrm{SMRT})$ in estrogen-dependent invasive breast cancer with histological grade. The other aims of study to evaluate the interaction between p53, Ki-67, Her-2/Neu expression and co-regulators with the histological grade. Analysis of these relationships will result in deeper understanding on the molecular basis of breast cancer incidence which can be associated with prognosis and prediction of the disease and evaluation of the targeted therapy in breast cancer. The coregulators and p53, Ki-67, Her-2/Neu were examined using immuno-histochemical technique toward paraffin block of 85 patients with estrogen receptor (ER) $\alpha$ positive. Relationships between these targets and histological grade were analyzed. We observed that SRC1 was associated with a high degree of malignancy and NCoR had a significant correlation with a low degree of malignancy. Interaction of SRC1 and NCoR with p53, Ki-67 and Her-2/Neu is significantly associated with the high degree of malignancy. This study provided evidence that SRC1 and NCoR were the independent prognostic factors. SRC1 was associated with the high grade malignancy (poor differentiation and in the other hand, the NCoR was associated with well differentiation histopathology. High expression of p53, Ki-67 and Her2/Neu which interact with SRC1 and NCoR were associated with a high degree malignancy.
\end{abstract}

Keywords: ER- $\alpha$, p53, Ki-67, Her-2/Neu, Histological Grade, Breast Cancer

\section{Introduction}

Cancer is a leading cause of death worldwide. An estimated 14.1 million new cancer cases and 8.2 million cancer-related deaths occurred in 2012, compared with 12.7 million and 7.6 million, respectively, in 2008. Breast cancer is also the most common cause of cancer death among women $(522,000$ deaths in 2012) and the most common cancer diagnosed in women in 140 of 184 countries around the world [1].

Estrogen is a key regulator of growth and differentiation of many physiological functions of target tissues, including 
male and female reproductive organs, breast, skeletal, nervous, cardiovascular, digestive and immune systems.

Endogenous estrogen has become a major concern in the last two decades that play a main role in breast cancer etiology [2]. In premenopausal women, the ovarial function under the control of cyclic pituitary gonadotropins is the predominant source of serum estrogen, and only a small amount derived from other organs. Conversely, in postmenopausal women, small amount of estrogen is produced from aromatization of adrenal and ovarian androgens on extragonad tissues such as liver, muscle and fat tissue [3].

Invasive carcinoma is a tumor that are detected by invasive malignant cells to the stromal. They were divided on the type of ductal and lobular. These tumors are associated with longterm growth with its major criteria is illustration of cytologic architectural and the spread toward stroma to other tissues (metastasis) [4].

Histopatogical evidence revealed that breast cancer is not a single disease, but rather a combination of different sub types. The major sub types are invasive ductal carcinoma (about 75\%), invasive lobular carcinoma (about 10\%) or a combination of both (approximately 5\%). The minor sub types are the mucinous, tubular, medullary, papillary and metaplastic breast cancer. Prognosis of breast cancer is determined by grouping based on age, tumor size, status of ER/PR, Her-2/Neu, luminal A (ER +/Her-2/Neu-), luminal B $(\mathrm{ER}+/ \mathrm{Her}-2 / \mathrm{Neu}+)$, basal-like (ER-/PR-/Her-2/Neu-), the transcription factor p53 mutations, KI-67, and others [5].

Estradiol, particularly $\beta$-estradiol hormone (E2), which is predominantly produced by the ovaries, affects epithelial breast cell proliferation, by stimulating the expression growth factors gene that can act as the procarcinogenic, called hormone stimulating cell proliferation [6]. A procarcinogenic can induce genetic damage which then affects cell division, thus increasing the potential of spontaneous mutation. The role of estradiol on cell proliferation is to facilitate mutation, increase already exist mutation or facilitate the expression of genetic errors by loss of heterozygosity due to a defect in DNA repair [7].

Generally, the effects of the ligand (estrogen) are mediated by estrogen receptors, which are a family of transcription factors. There are two types of estrogen receptors, namely $\mathrm{ER} \alpha$ and ER $\beta$. It is known that $17 \beta$-estradiol (E2) which binds to Er $\alpha$ will induce a conformational change in the receptor's hormone-binding domain and improve dimerization receptor, then the receptor is able to bind to the estrogen element receptors (EREs) that are generally located in the region of the target genes promoter target genes [8]. Approximately two-thirds of women with the breast cancer (aged $<50$ years) have ER positive, while about $80 \%$ of tumors in women aged $>50$ years have ER positive. This indicates that ER is one of prognostic and predictive biomarker that plays an important role in determining the treatment of invasive breast cancer [9]. ER is significantly associated with low and moderate grade malignancy, no necrosis, and older patients [4].
$\mathrm{ER} \alpha$ identification and methodologies development for detecting expression by hormone binding on tumor samples clinically shown as prognostic markers of therapeutic hormone response, therefore determination of $\mathrm{ER} \alpha$ has become a standard examination in clinical oncology. Selective Estrogen Receptor Modulators (SERMs), such as Tamoxifen is a hormone therapy that inhibits the ability of estrogen to bind to estrogen receptors through competitive inhibition, which in the breast act as a specific antagonist [10]. Approximately, nearly two-thirds of invasive breast cancers express $E R \alpha$, suggesting $E R \alpha$ expression is an important prognostic factor and a predictor of response to hormonal therapy [11]. Some proteins coregulator (coactivator and corepressor) have been found to modulate the activity of estrogen receptors $\operatorname{ER} \alpha$ and $\operatorname{Er} \beta$, for example $\mathrm{SRC} 1, \mathrm{CBP} / \mathrm{p} 300$ as coactivator or corepresor that suppresses transcription, such as NCoR, SMRT [12].

Mutations that occur in ER $\alpha$ may lead to resistance to hormonal therapy. Karnik et al. have identified an ER $\alpha 437$ stop mutation in one of the five breast tumor metastasis. The same mutation was identified in ER $\alpha 417$ stop that is identified at T47 DCO tamoxifen resistant cell line which showed clinical evidence of mutation where ER $\alpha$ plays an important role in hormonal therapy resistance. They also found changes in the expression of molecules coregulator during breast tumorigenesis resulting therapy resistance. For example, gene amplification $\mathrm{CBP} / \mathrm{p} 300$ (AIB1) resulted in estrogen growth independence and tamoxifen resistance. Tamoxifen binding to $\mathrm{ER} \alpha$ can recruit corepressor (eg. NCoR, SMRT) so that in case of reduction of corepressor expression, there will be no suppression of ER $\alpha$ activities [10]. This coregulator currently has become a concern and considered as significant prognostic factors because there is evidence which indicates that the imbalance of coactivator and corepressor will contribute to hormonal therapy resistance [13].

The Coactivator is categorized into several subgroups: family coactivator p160/SRC (SRC-1, GRIP-1, AIB-1), $\mathrm{CBP} / \mathrm{p} 300$, coactivator $\mathrm{CBP} / \mathrm{p} 300$ and SRC-associated Acetyltransferase, complex coactivator TRAP/drip. Coactivator is related to ER because of the agonist ligands. ER $\alpha$ affinity which interacts with AIB-1 is much more than those observed in ER $\beta$. For gene transcription in estrogen receptor thet is dependent / binding ligand (estrogen), there is recruitment of p160 coactivator that serves as an integral component in transcription of complex activation. When there is no estrogen, corepressor would bind ER and prevent gene activation downstream by various mechanisms. Coactivators then bind to histone deacetylation, joining basal transcription machinery and RNA processing, compete with active coactivator or take $\operatorname{Er} \alpha$ in the cytoplasm [13].

The main prognostic factors are a very strong predictor of mortality caused by breast cancer. Predictive factors are used in the determination of therapy response. Based on the grading system which is modified by Bloom - Richardson that assessed nucleus pleomorphic, tubular form and number of mitosis, then the percentage of 10 years survival rate are: 
$85 \%$ of women with low differentiated (grade I), $60 \%$ for women with moderately differentiated (grade II) and 15\% of women with poor differentiation (grade III) [14].

\section{Method}

This study was an observational study with cross sectional design to assess the association between the expression of estrogen receptor coregulator and histopathological grade in women with invasive breast cancer estrogen-dependent types.

Research Location and Time

This research was conducted in the Laboratory of Pathology Anatomy, Faculty of Medicine, Hasanuddin University Hospital and the Laboratory of Pathology Anatomy Dr. Wahidin Sudirohusodo in Makassar, Indonesia. The study was conducted after obtaining approval from local authorities.

\section{Population Research}

The study population was 85 women with invasive breast cancer who were enrolled in the patients registration at the Laboratory of Pathology Anatomy, Faculty of Medicine, Hasanuddin University Hospital and the Laboratory Pathology Anatomy Dr. Wahidin Sudirohusodo in Makassar, Indonesia.

\section{Laboratory examination procedures}

a Paraffin tissue blocks were selected for immunohistochemical examination estrogen receptors and receptor coregulator selected after the target sample slide has been seen again. Answer sheet data analysis results to retrieve data paraffin block registration numbers, age, macroscopic, microscopic and histopathological diagnosis. The blocks that will be used were selected to ensure the standard block and tumor representative, and if possible also taken part of benign epithelial (used as an internal positive control). Each paraffin block was cut with a microtome size of 4 microns and placed on an object glass. Immunohistochemical staining is using standard techniques. From each paraffin blocks were cut, the preparations were stained with hematoxylin eosin for histopathological examination, the preparations for staining receptor estrogen $\alpha$, four preparations for coloring coregulator estrogen receptor is the primary antibody SRC1, CBP/p300, NCoR, SMRT, the preparations for the staining of $\mathrm{p} 53$, the preparations for staining with primary antibody KI-67 and the preparations for the coloring of Her-2/Neu. Preparations are then examined under a microscope to determine the subtypes of breast cancer, histological grade, estrogen ekspresireseptor $\alpha, \mathrm{SRC1}, \mathrm{CBP} / \mathrm{p} 300, \mathrm{NCoR}$, SMRT, p53, Ki-67 and Her-2/Neu.

b Immunohistochemical method (Boenisch $\mathrm{T}$ et al, 2001): carried out using streptavidin-biotin-peroxidase labeled streptavidin-biotin (Dako, Carpinteria, USA). Before the dyeing process, each dosage preparations is deparrafinyzed with xylene for 15 minutes and rehydrated with $100 \%$ alcohol and the alcohol concentration is diluted to $90 \%, 80 \%, 70 \%$ and $60 \%$ for each 10 minutes. Then, the preparation is washed with dH20 2 times for 5 minutes and incubated with a solution of PBS for 5 minutes. Subsequently, the dosage preparations are put into a glass box containing citrate buffer and then inserted into the autoclave for 15 minutes for optimizing its antigenicity. The preparation is cooled at room temperature for 1 hour, and after dried briefly, is given the network boundary using pen smears. Preparations dH20 washed with PBS for 5 minutes and for 5 minutes before incubation with $0.3 \%$ hydrogen peroxidase for 15 minutes. After endogenous peroksidasenya blocked, the preparations were incubated with blocking solution for 30 minutes to block avidin that is found on the network. Furthermore, preparations were incubated overnight at a temperature of $-40^{\circ} \mathrm{C}$ with the primary antibody. The preparation is washed again 3 times with $\mathrm{dH} 20$ before incubated with secondary antibodies and streptavidin during each 30 minutes. Used for dyeing 3, 3 diamino benzidine tetrahydrocloride approximately 10 minutes to obtain coloring reaction that can be detected by microscopic examination. After that stained with hematoxylin again to clarify the nucleus of a cell for 30 seconds and washed with running water for 5 minutes. The preparation was dehydrated using alcohol concentration that is increased gradually from $70 \%, 80 \%, 90 \%$ to $100 \%$ for each 2 minutes. After that the preparation is inserted into xylene for 5 minutes. Finally, preparations were given etelan before it is closed with a glass deck. Immunohistochemical evaluation will be conducted by a researcher and a pathologist to get accurate results.

\section{Identification of Variables}

In this study, several variables can be identified as follows: 1. The independent variable is a group expression of estrogen receptor $\alpha, \mathrm{SRC1}, \mathrm{CBP} / \mathrm{p} 300, \mathrm{NCoR}, \mathrm{SMRT}, \mathrm{p} 53$ and $\mathrm{Ki}-67$, Her- $2 / \mathrm{Neu}$ and age groups $(<50$ years and $\geq 50$ years $)$ as a categorical variable (ordinal), 2. The dependent variable is the group histopathological degree of malignancy (grading) which includes categorical variables (ordinal). 3. Variable interaction namely the expression of p53, Ki- 67, Her-2/Neu.

Objective Criteria

1. The degree of invasive ductal breast carcinoma histopathology based system Notingham Modiffication system Scarff- Bloom- Richarson. (Fan, F \& Thomas, P. A. 2007, Rosai, J, 2011). Tubular formation: $>75 \%=$; $10-75 \%=2 ;<10 \%=3$ Pleomorphism cell of nucleus: small, unimorf $=1$; Vary the size medium $=2$; Vary significantly $=3$; Number of mitotic / high power field: 0 - 9 mitosis / $10 \mathrm{LPB}=1$; $10-19$ mitosis / $10 \mathrm{LPB}=$ 2 ; $>20$ mitosis / $10 \mathrm{LPB}=3$; Combination degrees of histopathologic: low grade $=3$ - 5; moderate grade $=6$ 7 ; high grade $=8-9$

2. Expression of Estrogen Receptor $\alpha, \mathrm{SRC} 1, \mathrm{CBP} / \mathrm{p} 300$, NCoR, SMRT, p53 and $\mathrm{Ki}-67$ is a protein Estrogen Receptor $\alpha$, SRC1, CBP/p300, NCoR, SMRT, p53 and $\mathrm{Ki}-67$ in the cell nucleus that is detected by the method 
immunohistochemistry. Estrogen expression of $\alpha$, SRC1, CBP/p300, NCoR, SMRT, p53 and Ki-67 tested positive when it looks brown in the core with a light microscope.

3. Estrogen $\alpha$ immunohistochemical examination, SRC1, $\mathrm{CBP} / \mathrm{p} 300, \mathrm{NCoR}, \mathrm{SMRT}$, p53, Ki-67 and Her-2/Neu is detection of antigen-antibody complexes Estrogen $\alpha$, SRC1, CBP/p300, NCoR, SMRT, p53, KI -67 and Her2 / Neu using monoclonal antibodies.

4. Imunoekspresi Estrogen $\alpha, \mathrm{SRC} 1, \mathrm{CBP} / \mathrm{p} 300, \mathrm{NCoR}$, SMRT, p53, Ki-67 and Her-2 / Neu expressed in semiquantitative estimate the scoring system:

5. o Estrogen- $\alpha$, SRC1, CBP/p300, NCoR, SMRT (Allred scoring) (Calhoun, $B$ et al, 2015): Intensity: $0=$ negative, 1 = weak, 2 = moderate, 3 = strong; the proportion of epithelial cells stained: $0=0 ; 1=>0$ $1 / 100 ; 2=>1 / 100-1 / 10 ; 3 \Rightarrow 1 / 10-1 / 3 ; 4=>1 / 3-$ $2 / 3 ; 5=2 / 3-1$. Total Score $=$ Intensity + The proportion of epithelial cells stained; Negative $=$ when a score of 0 - 2. Positive $=$ when a score $\geq 3$; Her-2 / Neu (ASCO / CAP HER2 testing guidelines) (Calhoun, B et al, 2015): the expression percentage of $>10 \%$ by the Intensity $0=$ negative, $+1=$ weak, $+2=$ moderate, +3 = strong; the positive is the value of +3 ; p53 and $\mathrm{Ki}-67$ : Proportion, $0=<10 \%, 1=10-25 \%, 2=26-50 \%, 3=>$ $50 \%$; positive is said to be a score of 2 and 3 .

Statistical analysis

Table 1. Frequency Distribution of SRC1 expression, CBP/p300, NC, SMRT, p53, KI-67, Her-2/Neu, and histological grade.

\begin{tabular}{|c|c|c|c|}
\hline Variables & & $\mathbf{N}$ & $\%$ \\
\hline \multirow[t]{2}{*}{ Age } & $<50$ years & 49 & 57,6 \\
\hline & $\geq 50$ years & 36 & 42,4 \\
\hline \multirow[t]{2}{*}{ SRC1 } & Negative & 27 & 31,8 \\
\hline & Positive & 58 & 68,2 \\
\hline \multirow[t]{2}{*}{ CBP/P300 } & Negative & 24 & 28,2 \\
\hline & Positive & 61 & 71,8 \\
\hline \multirow[t]{2}{*}{ NCoR } & Negative & 38 & 47,0 \\
\hline & Positive & 47 & 53,3 \\
\hline \multirow[t]{2}{*}{ SMRT } & Negative & 37 & 43,5 \\
\hline & Positive & 48 & 56,5 \\
\hline \multirow[t]{2}{*}{ p53 } & Negative & 40 & 47,1 \\
\hline & Positive & 45 & 52,9 \\
\hline \multirow[t]{2}{*}{ KI-67 } & Negative & 19 & 22,4 \\
\hline & Positive & 66 & 77,6 \\
\hline \multirow[t]{2}{*}{ Her-2/Neu } & Negative & 53 & 62,4 \\
\hline & Positive & 32 & 37,6 \\
\hline \multirow[t]{3}{*}{ Histological grade } & Low & 13 & 15,3 \\
\hline & Moderate & 46 & 54,1 \\
\hline & High & 26 & 36,6 \\
\hline
\end{tabular}

The collected data were analyzed using IBM Statistical Package for Social Sciences (IBM SPSS Software) version 20. Prevalence rates were calculated and compared for different schools using Pearson Chi-Square tests. The associations between the estrogen and histophatological grade were tested by logistic regression. Linear regression was used for analysis of continuous outcomes which provided estimated regression coefficients $(\beta)$ and their corresponding $95 \% \mathrm{CI}$. A p-value $<0.05$ was considered as significant result.

\section{Result}

We have observed the results of immunohistochemical examination of the 85 women with invasive breast cancer with a lifespan of between 27-57 years. In the grouping of age, $<50$ years were 49 people $(57.6 \%)$, and $\geq 50$ years were 36 people $(42.4 \%)$. Expression of SRC1 negative were 27 people (31.8\%), and the positive were $58(68.2 \%)$. Expression of $\mathrm{CBP} / \mathrm{p} 300$ negative were 24 people $(28.2 \%)$ and positive were $61(71.8 \%)$. Expression of NCoR negative were 38 people $(47.0 \%)$, and positive were $47(53,3 \%)$. Expression of SMRT negative were 37 people $(43.5 \%)$ and positive were $48(56.5 \%)$. Expression of p53 were negative as many as 40 people (47.1\%), and positive were 45 (52.9\%). Expression of KI-67 were negative as many as 19 people $(22.4 \%)$ and positive were 66 (77.6\%). Expression of Her2/Neu negative as many as 53 people $(62.4 \%)$ and positive were $32(37.6 \%)$. Based on the histological grade showed the subjects that included in the group of low-grade were 13 people $(15.3 \%)$, moderate grade as many as 46 people (54.1\%), and high grade as many as 26 people (36.6\%) (Table 1).

In observation of these results, we found a significant association between SRC1 Coactivator expression $(p=$ $0.001)$, corepressor NCoR $(p=0.010), \mathrm{p} 53(p=0.002), \mathrm{KI}-$ $67(p=0.012)$, Her-2/Neu $(p<0.001)$ and the histological grade. (Table 2)

Table 2. The frequency distribution of age groups, the expression of SRC1, CBP/p300, NCoR, SMRT, p53, Ki- 67, Her- 2 / Neu towards histological grade.

\begin{tabular}{|c|c|c|c|c|c|}
\hline \multirow[t]{2}{*}{ Variables } & & \multicolumn{3}{|c|}{ Histological grade } & \multirow[b]{2}{*}{$p$} \\
\hline & & Low & Moderate & High & \\
\hline \multirow[t]{2}{*}{ Age } & $<50$ years & $7(14,3 \%)$ & $29(59,2 \%)$ & $13(26,5 \%)$ & 0,536 \\
\hline & $\geq 50$ years & $6(16,7 \%)$ & $17(47,2 \%)$ & $13(36,1 \%)$ & \\
\hline \multirow[t]{2}{*}{ SRC1 } & Negative & $9(33,3 \%)$ & $15(55,6 \%)$ & $3(11,1 \%)$ & 0,001 \\
\hline & Positive & $4(6,9 \%)$ & $31(53,4 \%)$ & $23(39,7 \%)$ & \\
\hline \multirow[t]{2}{*}{ CBP/P300 } & Negative & $7(29,2 \%)$ & $12(50,0 \%)$ & $5(20,8 \%)$ & 0,069 \\
\hline & Positive & $6(9,8 \%)$ & $34(55,7 \%)$ & $21(34,4 \%)$ & \\
\hline \multirow[t]{2}{*}{$\mathrm{NCoR}$} & Negative & $4(10,5 \%)$ & $16(42,1 \%)$ & $18(47,4 \%)$ & 0,010 \\
\hline & Positive & $9(19,1 \%)$ & $30(63,8 \%)$ & $8(17,0 \%)$ & \\
\hline \multirow[t]{2}{*}{ SMRT } & Negative & $5(13,5 \%)$ & $17(45,9 \%)$ & $15(40,5 \%)$ & 0,216 \\
\hline & Positive & $8(16,7 \%)$ & $29(60,4 \%)$ & $11(22,9 \%)$ & \\
\hline \multirow[t]{2}{*}{ p53 } & Negative & $9(22,5 \%)$ & $26(65,0 \%)$ & $5(12,5 \%)$ & 0,002 \\
\hline & Positive & $4(8,9 \%)$ & $20(44,4 \%)$ & $21(46,7 \%)$ & \\
\hline \multirow[t]{2}{*}{ KI-67 } & Negative & $7(36,8 \%)$ & $8(42,1 \%)$ & $4(21,1 \%)$ & 0,012 \\
\hline & Positive & $6(9,1 \%)$ & $38(57,6 \%)$ & $22(33,3 \%)$ & \\
\hline \multirow[t]{2}{*}{ Her-2/Neu } & Negative & $9(17,0 \%)$ & $37(69,8 \%)$ & $7(13,2 \%)$ & $<0,001$ \\
\hline & Positive & $4(12,5 \%)$ & $9(28,1 \%)$ & $19(59,4 \%)$ & \\
\hline
\end{tabular}

$p=$ probability of $\mathrm{X}^{2}$ test results 
To understand the prognostic significance of the disease then histological grade has been categorized into 2 groups: low and high. There is significant correlation in SRC1 expression $(p=0.016), \operatorname{NCoR}(p=0.005), \mathrm{p} 53(p=0.001)$ and Her-2/Neu $(p=<0.001)$ toward histopathologic grade. Then we made a summary based on the significance above to see the variable of risk factor of SRC1, NCoR, p53 and Her2/Neu expression to histological grade (Table 3 ).

Table 3. Distribution of the frequency of SRC1, CBP/p300, NCoR, SMRT, p53, Ki-67, Her-2 / Neu expression risk factors towards histological grade (low and high groups).

\begin{tabular}{|c|c|c|c|c|c|c|c|}
\hline \multirow[t]{2}{*}{ Variable } & & \multicolumn{2}{|c|}{ Histological grade } & \multirow[t]{2}{*}{ OR } & \multicolumn{2}{|c|}{ 95\% CI for OR } & \multirow[t]{2}{*}{$p$} \\
\hline & & Low N (\%) & High N (\%) & & Low & Upper & \\
\hline \multirow[t]{2}{*}{ Age } & $<50$ yrs & $36(73,5)$ & $13(26,5)$ & 1,6 & 0,62 & 3,97 & 0,478 \\
\hline & $\geq 50 \mathrm{yrs}$ & $23(63,9)$ & $13(36,1)$ & & & & \\
\hline \multirow[t]{2}{*}{ SRC1 } & Negative & $24(88,9)$ & $3(11,1)$ & 5,3 & 1,42 & 19,50 & 0,016 \\
\hline & Positive & $35(63,3)$ & $23(39,7)$ & & & & \\
\hline \multirow[t]{2}{*}{ CBP/P300 } & Negative & $18(79,2)$ & $5(20,8)$ & 2,0 & 0,65 & 6,10 & 0,336 \\
\hline & Positive & $40(65,6)$ & $21(31,4)$ & & & & \\
\hline \multirow[t]{2}{*}{$\mathrm{NCoR}$} & Negative & $20(52,6)$ & $18(47,4)$ & 0,2 & 0,09 & 0,62 & 0,005 \\
\hline & Positive & $39(83,0)$ & $8(17,0)$ & & & & \\
\hline \multirow[t]{2}{*}{ SMRT } & Negative & $22(59,5)$ & $15(40,5)$ & 0,4 & 0,17 & 1,12 & 0,131 \\
\hline & Positive & $37(77,1)$ & $11(22,9)$ & & & & \\
\hline \multirow[t]{2}{*}{ p53 } & Negative & $35(87,5)$ & $5(12,5)$ & 6,1 & 2,03 & 18,49 & 0,001 \\
\hline & Positive & $24(53,3)$ & $21(46,7)$ & & & & \\
\hline \multirow[t]{2}{*}{ KI-67 } & Negative & $15(78,9)$ & $4(21,1)$ & 1,9 & 0,56 & 6,33 & 0,459 \\
\hline & Positive & $44(66,7)$ & $22(33,3)$ & & & & \\
\hline \multirow[t]{2}{*}{ Her-2/Neu } & Negative & $46(86,8)$ & $7(13,2)$ & 9,6 & 3,32 & 27,81 & $<0,001$ \\
\hline & Positive & $13(40,6)$ & $19(59,4)$ & & & & \\
\hline
\end{tabular}

$\mathrm{OR}=$ odds ratio, $\mathrm{CI}$ : Confidence interval, $\mathrm{N}$ : total number

Table 4. Summary of the results of multiple logistic regression analysis between the expression SRC1, CBP/p300, NCoR, SMRT, p53, Ki- 67, Her- 2 / Neu towards histological grade.

\begin{tabular}{lllllc}
\hline Variabel & $\boldsymbol{\beta}$ & $\mathbf{p ~ W a l d}$ & OR & \multicolumn{2}{c}{ 95\% CI for OR } \\
\hline & & & & Low & Upper \\
\hline SRC1 & 2,323 & 0,010 & 10,2 & 1,72 & 60,40 \\
NcoR & $-1,911$ & 0,008 & 0,2 & 0,04 & 0,61 \\
p53 & 1,633 & 0,023 & 5,1 & 1,26 & 20,86 \\
Her-2/Neu & 2,558 & $<0,001$ & 12,9 & 3,32 & 50,16 \\
Constanta & $-3,893$ & $<0,001$ & 0,02 & & \\
\hline
\end{tabular}

$\mathrm{OR}=$ odds ratio, $\mathrm{CI}$ : Confidence interval

The results showed a statistically significant correlation between the expression of SRC1 with histopathological degree $(p=0.01,95 \%$ CI for OR $=1.72$ to 60.40$)$. Expression of positive SRC1 gives 10.2 times greater chance of becoming group with higher histopathologic degrees than the negative expression. The variable NCoR expression showed a significant correlation with histopathologic degrees ( $p=0.008,95 \% \mathrm{CI}$ for $\mathrm{OR}=0.04$ to 0.61 ). Expression of positive NCoR provide 0.2 times greater chance of becoming group with lower histopathologic degrees than the negative expression. The variable p53 expression showed a significant correlation with histopathologic degrees $(p=0.023,95 \% \mathrm{CI}$ for $\mathrm{OR}=1.26$ to 20.86 ). Expression of $\mathrm{p} 53$ positive provide a 5.1 times greater chance of becoming group with higher histopathologic degrees than the negative expression. Similarly, the expression of Her-2/Neu showed significant association with histopathologic degrees $(p=<0.001,95 \% \mathrm{CI}$ for $\mathrm{OR}=3.32$ to 50.16). The expression of Her-2 / Neu positive provide 12.9 times greater chance of becoming group with higher histopathologic degrees than the negative expression. (Table 4).

Observations from the summary statistics show that there are four variables selected have a strong significant association with the degree of histopathological, including $\operatorname{SRC} 1(p=0.0100), \operatorname{NCoR}(p=0.008), \mathrm{p} 53(p=0.023)$ and Her-2/Neu $(p<0.001)$ (Table 4$)$. Based on these results, we observe interaction between p53, Ki- 67 and Her2 with SRC1 (Table 5) and NCoR (Table 6) in relation with low and high histopathological degree.

Table 5 showed that the positive expression of p53 that interact with SRC1 has a significant association $(p=0.05$, $\mathrm{OR}=4.7$ ) to the histophatological degree. As well as with KI-67 which has a significant relationship to the histophatological degree $(p=0.03, \mathrm{OR}=5.1), \mathrm{Her}-2 / \mathrm{Neu}(p$ $=0.004$, OR $=13.6$ ). 
Table 5. Distribution of the frequency of interactions between the expression of p53, Ki-67 danHer-2 / Neu with SRC1 towards the histological grade (low and high groups).

\begin{tabular}{|c|c|c|c|c|c|c|c|c|c|}
\hline \multirow{2}{*}{ Variables } & & & & \multicolumn{2}{|c|}{ Histological grade } & \multirow[t]{2}{*}{ OR } & \multicolumn{2}{|c|}{$95 \%$ CI for OR } & \multirow[t]{2}{*}{$P$} \\
\hline & & & & Low N (\%) & High N (\%) & & Low & Upper & \\
\hline \multirow[t]{4}{*}{ P53 } & Negative & SRC1 & Negative & $16(94,1)$ & $1(5,9)$ & 3,3 & 0,34 & 33,26 & 0,2 \\
\hline & & & Positive & $19(82,6)$ & $4(17,4)$ & & & & \\
\hline & Positive & & Negative & $8(80,0)$ & $2(20,0)$ & 4,7 & 0,80 & 25,60 & 0,05 \\
\hline & & & Positive & $16(45,7)$ & $19(54,3)$ & & & & \\
\hline \multirow[t]{5}{*}{ KI-67 } & Negative & SRC1 & Negative & $9(90)$ & $1(10)$ & 4,5 & 0,37 & 54,15 & 0,2 \\
\hline & & & Positive & $6(66,7)$ & $3(33,3)$ & & & & \\
\hline & Positive & & Negative & $15(88,2)$ & $2(11,8)$ & 5,1 & 1,06 & 25,15 & 0,03 \\
\hline & & & Positive & $29(59,2)$ & $20(40,8)$ & & & & \\
\hline & Negative & SRC1 & Negative & $16(94,1)$ & $1(5,9)$ & 3,2 & 0,35 & 28,94 & 0,3 \\
\hline \multirow[t]{3}{*}{ Her-2/Neu } & & & Positive & $30(83,3)$ & $6(16,7)$ & & & & \\
\hline & Positive & & Negative & $8(80,0)$ & $2(20,0)$ & 13,6 & 2,15 & 85,85 & 0,004 \\
\hline & & & Positive & $5(22,7)$ & $17(77,3)$ & & & & \\
\hline
\end{tabular}

$\mathrm{OR}=$ odds ratio, $\mathrm{CI}$ : Confidence interval, $\mathrm{N}$ : total number

Table 6. Distribution of frequency of interaction between the expression of p53, Ki- 67 danHer - 2 / Neu with NCoR towards the degree of histopathological (low and high groups).

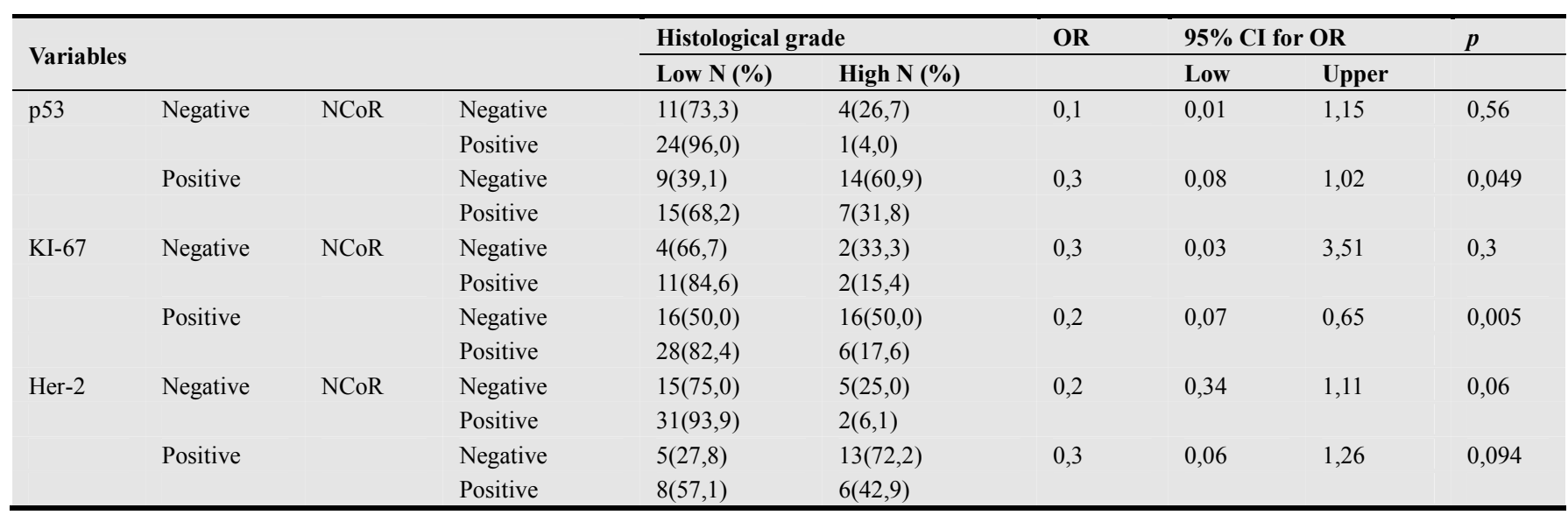

$\mathrm{OR}=$ odds ratio, $\mathrm{CI}$ : Confidence interval, $\mathrm{N}$ : total number

There is a significant correlation between interaction of p53 to NCoR ( $p=0.049)$, and KI -67 to NCoR $(p=0.005)$ towards the histopathological grading. The expressions of Her-2/Neu have a potential significance relationship: a decline of up to $50 \%$ on the interaction of Her-2 negative expression with $\mathrm{NCoR}$ group low grade histopathological as many as 46 subjects $(86.8 \%)$ in comparation to Her- 2 positive in 13 subjects $(40.6 \%)$.

\section{Discussion}

Breast cancer is a disease that has various subtypes differentiation which has been significantly proven cellular and molecular, so the management strategies should pay attention to this diversity. Histopathologically, the major subtypes are invasive ductal carcinoma (75\%), lobuler invasive carcinoma $(10 \%)$ or a combination of both $(5 \%)$, while the minor population is mucinous type, tubular, medullary, papillary and metastatic breast cancer. But despite having same degree of histopathological malignancy, the prognosis of the disease can be different depends on the expression of tumor biomarker, in relation to therapy and tumor relapse.

The invasive ductal tumors with positive estrogen receptor $\alpha($ ER- $\alpha)$ have a better prognosis than those who don't have this expression because of the anti-hormonal sensitivity. Patients with invasive ductal breast carcinoma who have high expression of Her-2/Neu (20-30\%) is related with high grade malignancy, but may respond to anti-Her2 therapy. Moreover, activity on the estrogen receptor signaling pathway is affected by the genomic sub-types coregulator which will activate or inhibit transcription, which is one of the causes of anti-hormonal resistance despite positive expression of ER- $\alpha$ [5].

Estrogen, particularly $\beta$-estradiol (E2), is a steroid hormone which has a very important role in promoting proliferation both in normal cells and breast neoplasm. Effect of estrogen in the proliferative activity of mammary epithelial cells is mediated by direct stimulation with binding to specific receptors estrogen. This study focuses on signal transcription pathway ER- $\alpha$ which involves the genomic coregulator ER- $\alpha$. As a prognostic factor, expression ER- $\alpha$ is 
positively associated with a good prognosis, although it can change when evaluating initial treatment interval with tumor relapse. The expression of ER- $\alpha$ also correlate positively with a good prognosis, low grade malignancy, low tumor proliferation index, and a lower rate of gene mutation. As a predictor, positive expression of ER- $\alpha$ - is related to response of hormonal based therapy so that ER- $\alpha$ status is used to determine the appropriate treatment method [15].

Transcriptional activity in target genes occurs in cooperation with coactivator proteins that interact directly or indirectly with the genes responds to estrogen to facilitate proliferation of the breast tissue. Physiologic functions of estrogen signaling pathway is used in breast cancer to promote tumor progression. Majority of breast cancers (about $70 \%$ express estrogen receptor ER- $\alpha$ and immunohistochemical detection of this receptor can be a prediction of hormonal therapy response [16]. Up to now, it is believed that the action of estrogen is through single core estrogen receptors that activate transcription of the specific target genes. Nevertheless, there is evidence that indicates a membrane receptor can bind to and work on the alternative mechanism of second messenger signaling pathways (nongenomic) that stimulates a cascade of proliferation. It was found that the cells with the expression of ER- $\alpha$ negative is located in breast tissue which responds to estrogen through this or other signal pathway. This showed that a paracrine mechanism is important in mediating cell proliferation [17]. Gene consists of a DNA segment to that is going to be transcribed into RNA. It starts from the transcription initiation site (called the 5 'flanking region) to a transcription termination (called $3^{\prime}$ flanking region). Although 5 'and 3' flanking region cannot be transcribed into RNA, they have DNA sequences called regulatory elements that control gene transcription. 5' region contains a DNA sequence as a promoter that bind transcription factor which ensued deployment of the RNA polymerase II enzyme, that transcribes mRNA sequence. There are three mechanisms of transcriptional activation by transcriptional activator binding with direct or indirect (through coactvator) specific enhancer, which are (1) recruit RNA polymerase to the promoter (the recruitment of the basal transcription machinery), (2) recruiting histone Acetyl transferase that remodel chromatin and (3) stimulated phosphorylation of C-terminal domain (CTD) to the RNA polymerase [18].

ER- $\alpha$ plays a role in the regulation of transcription by activating ligand-dependent transcription. The structure of ER- $\alpha$ in the transcription function involves two different domains: activator function-1 (AF 1) at the NH2 terminus and AF2 in the ligand binding domain (LBD). Both of these domains interact synergistically. AF2 domain contains conservation of amphifatic $\alpha$ helix that interacts with Coactivator to promote transcription [16].

Activity of ligand dependent ER- $\alpha$ is described as a model in which ER- $\alpha$ is located in the cytoplasm with low hormone concentrations. Ehen hormonal binding occurs, transcriptional activity occurs through phosphorylation process which is made possible through the ER- $\alpha$ folds becomes active conformation that is able to be dimerized. Complex ER- $\alpha$ with ligand (estrogen) is separated by Heat Shock Protein (HSP) 90 and then translocated to the nucleus and bond directly to the estrogen response element (ERE) on specific DNA sequences that is promoter region of the estrogen responsive gene [19].

Coactivator and corepressor that are bond to ER- $\alpha$ are the element of regulator, which interact in specific DNA sequences in the the same place/location (cis-acting factors) that can stimulate (bonds with enhancer) or inhibit (bonds with silencer) transcription of the gene target (Igarashi, 2012). Elements of the regulator in this study are Coactivator SRC-1 (steroid receptor coactivator 1), CBP/p300 (CREBbinding protein) that stimulate transcription and NCoR (Nuclear receptor corepressor), SMRT (silencing mediator of retinoid and thyroid receptors) as corepressor that inhibit transcription [18].

Promoter that binds to ER induced transactivation function by recruiting histone activity Acetyltransferase (HAT) containing coactivator eg, SRC-1, SRC-2, AIB-1. HAT activity containing coactivator induces histone acetylation resulting in open chromatin configuration and recruits the basal transcription machinery. ER- $\alpha$ is also a repressor media on specific genes through a bind induction with histone deacetylase activity (HDAC) that contain corepressor complex that cause closed chromatin conformation [16].

The results showed a significant correlation between SRC1 toward histological grade $(p=0.001)$. SRC1 is a phosphoprotein and members of the p160 protein family coactivator. The multiple logistic regression test showed positive expression of SRC1 which has 10.2 times greater chance of becoming a high degree of histopathological compared to negative expression. Research by FJ Fleming et al (2004) showed patients with high expression of Her-2/Neu and SRC1 have a greater likelihood of recurrent disease compared to Her-2/Neu (+) and SRC1 (-), which means that SRC1 can be prediction indicator and a therapeutic target in breast cancer. This also shown in this study, where interaction expression of $\mathrm{Her}-2 / \mathrm{Neu}(+)$ with SRC1 (+) shows the relation with the higher histopathological grade. ER- $\alpha$ can be the target of selective estrogen receptor modulators (SERM-s) as antagonists, for example Tamoxifen, which competes with estrogen and alter the conformation of the ligand-binding domain (LBD) of the receptor, and then interact with corepressor to inhibit transcription. Thus the change in concentration and activity of proteins in complex Coactivator ER estrogen-response elements can be very important in the changing profile of estrogen receptor modulator as an agonist or antagonist in hormonal therapy resistant tumors. Activity and expression levels may increase ER activity or modulate tamoxifen agonist / antagonist activity. In breast cancer, tamoxifen acts predominantly as an ER antagonist, blocks the activity of ER and furthermore decrease the growth of tumor cells. With the existence of high expression coactivator activity, tamoxifen can act as an agonist, promote transcriptional activity of ER, followed by growth of cancer cells. Even more, coactivator 
over expression is associated with tamoxifen resistance. Coactivator over expression in patients who received tamoxifen therapy, had poor results mainly attributed to the interaction of the Her-2/Neu high expression [20]

Interaction with p53 $(+)$ indicates significant figures that is strongly related to the incidence of high grade malignancy. p53 mutations occur in $30 \%$ of cases of breast cancer, so it has a strong exploration for histopathologic factors investigation. P53 mutation is found elevated in triple negative breast cancer (the expression of ER, PR and Her-2 / Neu negative). In the in vitro study of breast cancer derivative (cell lines) from MCF-7 showed p53 mutations are more resistant to the cytotoxic effects of 4-hydroxy-tamoxifen compared to the wild type p53. The meta-analysis result of 4683 patients with breast cancer in premenopausal women who have p53 over-expression p53 is associated with a poor outcome when using tamoxifen after chemotherapy [21].

$\mathrm{CBP} / \mathrm{p} 300$ is a transcriptional Coactivator and family members of histone acetyltrasferase. This Coactivator plays an important role in the transcription process and catalyze histone acetylation by histone Acetyltransferase activity. Research by Xiang-sheng et al (2011) also suggested a link relating to the histopathologycal degree of has a poor prognosis in breast cancer. $\mathrm{CBP} / \mathrm{p} 300$ is also a strong cofactors associated with p53 in invasive ductal carcinoma that made this coactivator an independent biomarker of poor prognosis. In this study, the statistical tests showed that high expression of the $\mathrm{CBP} / \mathrm{p} 300$ had a potential significant relationship to the histopathological degree of but not meaningful as a risk factor for histopathological degrees.

Mechanism of action of corepressor on ER- $\alpha$ is by (A) recruiting histone deacetylase and nucleosome remodeling (eg on NCoR and SMRT) so that transcriptional activity is inhibited, (B) interacting with basal transcription factor, for example NCoR interacts with TFIIB, TAFII32 and TAFII70 factors, thereby locking compound is not functioned or becoming conformation form that is not conducive for transcription, (C) competing with coactivator, (D) inhibiting RNA processing, (E) inhibiting dimerization of ER- $\alpha$ and bond with DNA (DNA-binding). In this study, corepressor $\mathrm{NCoR}$ is significantly related with the histopathological degree, where the higher the expression, the lower the malignancy degree, so it is associated with good pronosis. NCor and SMRT interact in the promoter and with large shapes of complex corepressor they will reduce basal transcription. Corepressor will decrease transcription gene activity through its link to histone deacetylase complex (HDAC) [22].

NCoR and SMRT is strongly binding to ER- $\alpha$ in the presence of antiestrogen (tamoxifen). Overexpression of corepressor will increase antagonist activity of antiestrogen, in the other hand, negative corepressor activity will diminished antagonist activity. The low level of corepressor expression associated with tamoxifen resistance [20].

This study is also showed a significant relationship between the interaction expression of positive p53 expression with positive $\mathrm{NCoR}$ towards higher histopathological degree.
This may indicate that the activity of p53 transcriptor is more dominant than NCoR thus it intensified the effect of transcriptional activation. Similarly, the higher interaction of KI-67 with NcoR, the higher the malignancy grade.

\section{Conclusion}

There is a coregulator role of SRC1 and $\mathrm{NCoR}$ in relation towards histological grade. The higher expression of SRC1 is associated with the high histological grade (high differentiation), in the contrary, the higher expression of NcoR, the lower histological malignancy grade (low differentiation).

There is an interaction relation between p53, Ki-67 and Her-2/Neu with SRC1 and NCoR towards the histological grade. High expression of p53, KI-67 and Her-2/Neu that interacts with SRC1 is related with higher histological grade. High interaction of p53, Ki-67 and Her-2/Neu with NcoR is also related to high histological grade.

Based on the conclusion, we suggest examination of immunohistochemical detection of SRC1 and NCoR expression in patients with invasive breast carcinoma as a determinant factor of prediction and prognosis of the disease. Advanced research related to hormonal therapy and targeted response to tumor relapse in patients with invasive breast carcinoma is much more needed in order to determine the appropriate therapeutic target strategy.

\section{References}

[1] Ferlay J, Steliarova-Foucher E, Lortet-Tieulent J, Rosso S, Coebergh JW, Comber $\mathrm{H}$, et al. Cancer incidence and mortality patterns in Europe: estimates for 40 countries in 2012. European journal of cancer. 2013; 49(6): 1374-403.

[2] Samavat H, Kurzer MS. Estrogen metabolism and breast cancer. Cancer letters. 2015; 356(2 Pt A): 231-43.

[3] Campos SM. Aromatase inhibitors for breast cancer in postmenopausal women. The oncologist. 2004; 9(2): 126-36.

[4] Rosai J.; In: Surgical Pathology. Ackermann. The Breast. 9th ed. St. Lois: Mosby. 2004: 1802-1826.

[5] Lee AV, Oesterreich S, Davidson NE. MCF-7 cells--changing the course of breast cancer research and care for 45 years. J Natl Cancer Inst. 2015 Mar 31; 107(7).

[6] Lester S.; In: Robbins and Cottran. Pathologic Basis of Disease. 7th ed. Philadelphia: 2005: 1129-1151.

[7] Liehr, J. Is Estradiol a Genotoxic Mutagenic Carcinogen? Endocrine Reviews 21 (1): 2000: 40-5.

[8] Smith L. C; O’Malley W. B. Coregulator Function: A key to understanding tissue specificity of selective receptor modulators. Texas: The Endocrine Society. 2003. 45-63.

[9] Allred DC, Anderson SJ, et al. Adjuvant tamoxifen reduces subsequent breast cancer in women with estrogen receptorpositive ductal carcinoma in situ: a study based on NSABP protocol B-24. J Clin Oncol. 2012 Apr 20; 30(12): 1268-73. 
[10] Herynk HM, Fuqua AW, et al. Estrogen Receptors in Resistance to Hormone Therapy. USA: Landes Bioscience and Springer Science. 2007: 131-135.

[11] Graham DJ, et al; Thoughts on Tamoxifen resistent breast cancer. Are regulators the answer or just a red herring? Journal of Steroid Biochemistry and Molecular Biology. Colorado. 2000: 1-4.

[12] Germain, Doris; Estrogen Carcinogenesis in Breast Cancer. New York: Elsevier Inc. 2011; p 473-481.

[13] Green AR, et al; The Prognostic significance of steroid receptor co-regulators in breast cancer: co-repressor NCOR2/SMRT is an independent indicator of poor outcome. Nottingham: School of Molecular Medical Sciences Nottingham University Hospitals. 2007: 428-436.

[14] Damjanov I, Fang F.; Cancer Grading Manual; University of Kansas School of Medicine. Kansas City, 2005: 75-80.

[15] Herynk, MH; Fuqua AW; Suzanne; Estrogen Receptors in Resistance to Hormone Therapy. USA: Landes Bioscience and Springer Science. 2007: 131-135.
[16] Douglas, Potter, David Yee; Steroid Receptors In Breast Cancer. Philadelphia. 2009: 485-494.

[17] Ghayad S et al; Prognostic and Predictive Factors in Breast Cancer. $2^{\text {nd }}$ ed. London. 2008: 1008-117.

[18] Igarashi P.; In: Medical Physiology: Regulation Of Gene Expression. Philadelphia. 2012: 75-105.

[19] Russo J et al; In: Endocrinology: Adult and Pediatric, $6^{\text {th }}$ ed. Philadelphia. 2010: 2265-2279.

[20] Nardone, A; De Angelis C; Trivedi, Meghana; Osborne, Kent C; Schiff, Rachel; The Changing Role of ER in Endocrine Resistance, Elsevier Ltd, Orginal Article. 10 Agustus 2015: $560-566$.

[21] Varna $M$, et al. Changes in allelic imbalances in locally advanced breast cancers after chemotherapy. Br. J. Cancer. 2007 Oct 22; 97(8): 1157-64.

[22] Busillo JM, et al; Steroid Hormone Action. Yen \& Jaffe's Reproductive Endocrinology 7th Edition. Philadelphia. Saunders. 2014: 93-107. 